\title{
Top-Down and Bottom-Up Lockdown: Evidence from COVID-19 Prevention and Control in China
}

\author{
Xiaoming Zhang ${ }^{1,2} \cdot$ Weijie Luo ${ }^{3,4}$ (D) Jingci Zhu ${ }^{5,6}$ \\ Accepted: 27 November 2020 / Published online: 5 January 2021 \\ (C) Journal of Chinese Political Science/Association of Chinese Political Studies 2021
}

\begin{abstract}
Utilizing national migration data regarding the outbreak of the novel coronavirus (2019-nCoV), this paper employs a difference-in-differences approach to empirically analyze the relationship between human mobility and the transmission of infectious diseases in China. We show that national human mobility restrictions ascribed to the first-level public health emergency response policy effectively reduce both intercity and intracity migration intensities, thus leading to a declining scale of human mobility, which improves the effectiveness in controlling the epidemic. Human mobility restrictions have greater influences on cities with better economic development, denser populations, or larger passenger volumes. Moreover, mobility restriction measures are found to be better implemented in regions with increased public awareness, or with provincial leaders who have healthcare crisis management experience, local administrative experience, or the opportunity to serve a consecutive term.
\end{abstract}

Keywords Pandemic prevention and control $\cdot 2019-n C o V \cdot$ Human mobility

Weijie Luo

luoweijie@cufe.edu.cn

1 School of Public Policy \& Management, Tsinghua University, Beijing, People's Republic of China

2 Economic Department, University of Chinese Academy of Social Sciences, Beijing, People's Republic of China

3 Center for China Fiscal Development, Central University of Finance and Economics, Beijing, People's Republic of China

4 Department of Economics and Related Studies, University of York, York, UK

5 National School of Development, Peking University, Beijing, People's Republic of China

6 School of Foreign Studies, Central University of Finance and Economics, Beijing, People's Republic of China 


\section{Introduction}

Since the outbreak of the novel coronavirus (2019-nCoV), over 33 million people have been infected, and the number of deaths from this disease has exceeded one million worldwide as of the end of September 2020. In the United States, 2019-nCoV has infected over seven million people, ${ }^{1}$ while no turning point in confirmed infections has been observed in the world. With the shock brought by the pandemic of COVID-19, the world economy has experienced a very large jolt and decline. International crude oil prices tumbled, and the GDP growth rate became negative. Based on the forecast of the International Monetary Foundation, the economic loss for the whole world will exceed 9 trillion US dollars. In the context of the global pandemic, control of COVID-19 has great influences on economic and political recovery and globalization, especially with concerns about the US-China relationship [1-4].

China, as the first country to suffer from COVID-19, has taken rapid actions to prevent and control the virus owing to its emergency health policy. The launch time of the First-level Public Health Emergency Response Policy dated back to 2007, when the Chinese government had acquired experience with the severe acute respiratory syndrome (hereafter SARS) and initiated the Law of the People's Republic of China on the Response to Emergencies. During the period of the first-level public health emergency response, local governments needed to delimitate the control area, lock down the epidemic area, take compulsory actions (i.e., constraining or suspending work, production, and business), implement human mobility restrictions, establish quarantine stations, and collect information from each community. With the outbreak of COVID-19, the number of newly confirmed infected cases was increasing in China and raised the attention of the central government. As a result, an emergency health policy was implemented, and China enacted human mobility restrictions.

Since the lockdown of Wuhan, 31 provinces in mainland China have activated firstlevel public health emergency responses to restrict human mobility and gatherings by setting up traffic points and quarantine stations in city streets and rural roads. The COVID-19 pandemic reached its turning point on February 18, 2020, after which people resumed work, production, and school in a step-by-step manner. Under the circumstances in which the spread of 2019-nCoV has been controlled gradually, China exports respirator masks and other medical components and plays an active role in fighting against 2019-nCoV. Figure 1 demonstrates the trends of newly confirmed cases in China, the United States, and the world. Although China is a country with a large population and the outbreak met the Spring Festival travel rush, China still obtained great success in fighting against the transmission of COVID-19, which can serve as a reference for other countries that are currently suffering from the pandemic. Studying the experiences related to the success in preventing and controlling the pandemic in China has important implications for the prevention and control of COVID-19 in the rest of the world, especially when no effective vaccines are currently available.

Most existing literature focuses on the blocking effects of traffic control of the epicenter, Wuhan, but ignores the contributions of national human mobility restrictions to the prevention and control of COVID-19. Before the lockdown of Wuhan,

\footnotetext{
${ }^{1}$ According to statistics from the end of September 2020.
} 


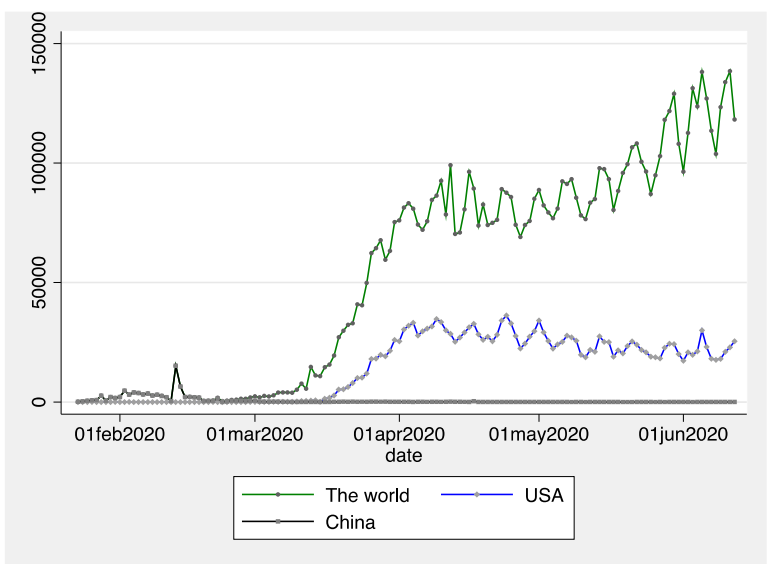

Fig. 1 Newly confirmed cases in China, the USA, and the world

approximately 5 million people left Wuhan, and most cities had inflows of infectious cases. If national human mobility restrictions were not implemented, then COVID-19 in China could not have been suppressed in such a short period. Therefore, one key motivation of this paper is to examine the effect of national human mobility restriction policies (i.e., the first-level public health emergency response, established after the 2003 SARS crisis) on the spread of COVID-19 and to investigate the rigidity of prevention and control measures, as the implementation of this policy implies that we have to control the virus at the cost of temporary but sizable economic loss. Based on this, this paper uses human mobility data on 297 cities in China derived from Baidu's migration database to empirically study the impacts of national human mobility restrictions.

Moreover, we further estimate the heterogeneous effects of human mobility restrictions in China, utilizing regional socioeconomic factors, public awareness and local leaders' characteristics. First, this paper splits the sample according to regional socioeconomic factors, including highway passenger capacity, income level, and population density. We examine whether human mobility restrictions have higher efficiency in cities with larger passenger volumes, better economic development, or denser populations. Second, this paper explores the heterogeneous effects on public awareness. Several cities in China were affected by the SARS crisis in 2003, and consequently, public awareness regarding sanitation in these cities dominates that in other cities. Third, as the emergency response policy supervision of local governments is led by the provincial government, local leaders play a key role in carrying out the mobility restriction policy. We then analyze the heterogeneity of provincial leaders' work experience and tenure (i.e., healthcare crisis management experience, local administrative experience and the chance to serve a consecutive term) to present the heterogeneous impacts on the implementation of epidemic prevention and control.

Our analysis makes use of the human mobility data and adopts the difference-indifferences approach to document three main findings. First, the policy of national human mobility restrictions effectively reduces the intercity and intracity migration intensities, thus leading to a decreasing scale of newly confirmed cases, which 
improves the effectiveness in controlling the epidemic. Second, the first-level public health emergency response exerts a greater impact on large cities with considerations of transportation, economic development and population density. Third, mobility restriction measures are found to be better implemented in provinces with SARS cases in 2003, or with provincial leaders who have healthcare crisis management experience, local administrative experience, or the chance to serve a consecutive term.

We believe that this paper makes two crucial contributions to the current literature. First, this paper finds that the intensity of human mobility restriction measures varies among different regions since the emphasis of local governments and their citizens' public awareness differ. Second, the heterogeneous impacts of human mobility restrictions on preventing and controlling the pandemic are analyzed, which could provide practical ways for countries that are currently suffering from the virus and for China to fight against other possible epidemic crises in the future.

The rest of the paper is organized as follows. The next section introduces the existing literature. Section 3 presents the data and identification strategy. Section 4 illustrates the empirical results, and the last section concludes.

\section{Literature Review}

Human mobility has important effects on the spread of infectious diseases. The earliest existing study on the theoretical model of epidemics was conducted by Kermack and McKendrick [5], who first provided the susceptible-infected-recovered (SIR) model. However, his study lacks analysis of the effects of policy and suffers from potential endogeneity problems. Camitz and Liljeros [6] utilize a stochastic simulation model with Swedish data and find that a travel ban significantly reduces the possibility of spread of epidemics such as SARS. Ferguson et al. [7] find that border and travel restrictions can effectively control the spread of epidemics, but school closure has limited impacts on the overall attack rates with epidemic simulation methods using the United Kingdom and the United States as examples. Bajardi et al. [8] point out that governments should take control of human mobility in order to delay or contain the spread of pandemics, considering the emergence of H1N1 influenza in 2009. Based on the findings that travel restrictions have effects on containing pandemics, some scholars then analyze the relationship between economic activities and the spread of epidemics, especially the relationship between trade and pandemic transmission. Oster [9] finds that there is a positive relationship between international trade and new HIV infections using real HIV infections estimated by the death rates in Africa. Adda [10] use data on viral diseases in France in the last 25 years to analyze the relationship between economic activities and disease spread. The estimations suggest that with the development of transportation infrastructure and the increase in trade, the scale of spreading of viruses will increase dramatically. With data on influenza spreading in the US during 2002-2010, Charu et al. [11] find that, compared with air transmission, the main transmission channel for influenza is human mobility via commuting.

More recently, Kraemer et al. [12] utilize real-time mobility data and case data, including travel history and characteristics, with a generalized linear model and argue that the control measures in China substantially mitigate the spread of COVID-19. Hadjidemetriou et al. [13] provide evidence that the UK government's control 
measures in reducing human mobility, based on the Apple mobility trends report (i.e., human mobility trend data on walking, driving and using public transport), have a crucial impact on reducing COVID-19-related deaths.

With the existing literature, it is of great importance to implement human mobility restrictions to contain the spread of 2019-nCoV during its outbreak [14, 15]. By analyzing the lockdown of Wuhan on January 23, 2020, Fang et al. [16] find that the lockdown reduces outflows from Wuhan by $56.4 \%$ and predict that the infected population will increase by $64.8 \%$ outside Hubei Province and $52.6 \%$ outside Wuhan but within Hubei if a human restriction policy has not been implemented. Through the analysis of human mobility and infection data, Chinazzi et al. [17] find that Wuhan's travel restrictions have crucial impacts on the control of COVID-19 in both China and the world, but their international influences are more significant. Tian et al. [18] demonstrate that Wuhan's lockdown delays inflows of infected individuals by 2.91 days and results in gains in time for some cities' medical system to make preparations, thus reducing the scale and intensity of the outbreak. Chudik et al. [19] extend the standard SIR model and find that mandating social distancing measures could effectively flatten the epidemic curve with the cost of unemployment. The results also show that the exposure rates in Hubei Province are 40 times higher than those in other provinces in China, while the rates in European countries are 3-5 times larger than those in Hubei, which could also explain the rapid spread of COVID-19 in Europe.

The transmission of infected diseases is also affected by city-level differences, which leads to a growing body of literature focusing on heterogeneity. Knittel and Ozaltun [20] indicate that higher amounts of public transportation usage are correlated with higher death rates. Based on such results, human mobility restrictions and suspensions of work, production and business are necessary. Kuchler et al. [21] use anonymized and aggregated data from Facebook to test the relationship between social ties and the spread of the pandemic. The results show that areas with stronger social ties to an epicenter have more confirmed cases during the pandemic, which emphasizes the importance of social distancing. Qiu et al. [22] point out that human mobility restrictions at the epicenter of an outbreak have the largest impact. In addition, some researchers investigate the heterogeneous effectiveness of restriction policies. Controlling for more standard epidemiological factors, Brown and Ravallion [23] find that richer counties tend to see greater gains in social distancing and lower infection rates.

From the perspective of policy enforcement, apart from the existing literature focusing on the adoption and spread of pandemic control policies related to national characteristics [24-26], we adopt a relative micro-perspective, paying attention to the influences of local governors' characteristics on policy outcomes. The existing literature provides evidence that the characteristics of local official leaders could affect the enforcement of a certain policy [27, 28], which logically includes the restriction policy effect. Specifically, the background of political leaders, including their education and work experiences, could influence their political decisions [29-32]. Examining the provincial leaders' education background and work experiences related to emergency control is necessary under such circumstances. In addition, the enforcement of the restriction policy also relies on the response from citizens. If citizens realize the severity of the pandemic, then they will be more willing to follow government orders and adhere to the social distancing policy. As far as we know, there is limited research on 
how public awareness could affect the impact of restriction policies, and we will further test this effect in the following section.

With the first-level public health emergency response being implemented consecutively by all provinces in China, this paper aims to quantify the impacts of human mobility restrictions from a more profound perspective of heterogeneous effects to fill the existing research gaps.

\section{Data and Econometric Specification}

\section{Data and Descriptive Statistics}

With the existing literature focusing mostly on the impacts of Wuhan's lockdown on human mobility, this paper instead utilizes data on human mobility and infected cases in 293 cities and four provincial-level municipalities in China to empirically analyze the impacts of the first-level public health emergency response on intercity and intracity human mobility. We further explore its influences on newly infected cases with a difference-in-differences method under the control of weather conditions.

The variables used in the empirical analysis are derived from the following data sources. The data on human mobility, including population inflows, outflows, and intercity data, are extracted from Baidu's migration database. This database collects the positioning data of all users of Baidu's map, an application that has over 400 million active users, to calculate the index related to human mobility in different areas. With the web crawler of Python, the data utilized in this paper cover 297 cities over 31 provinces between January 1, 2020, and February 29, 2020, and the corresponding lunar dates of last year (between January 12, 2019, and March 12, 2019). The in-migration index and out-migration index indicate an average human mobility level of 90,848 person movements, while the within-city migration index indicates a human mobility level of 2,182,264 person movements on average according to Fang et al. [16]. From this essential database, we construct the variables InterFlow and IntraFlow, which capture the inter- and intracity human mobility situation.

The data on the newly confirmed infected cases are taken from the COVID-19 and Economic Research Database, a subdatabase of the China Stock Market and Accounting Research Database (CSMAR). Data on weather conditions come from the State Meteorological Administration. Utilizing the Selenium database, we employ the crawler with the Webdriver application to collect weather condition data, which assists us in constructing variables on weather temperature, wind speed and wind direction. Resume data for provincial-level political leaders, including their education background and track records, are derived from the Portal of the Central People's Government of the People's Republic of China. These essential data are utilized to estimate the heterogeneity of treatment effects of the first-level public health emergency response.

Table 1 demonstrates the descriptive statistics for the intercity migration intensity, intracity migration intensity, newly confirmed cases, and weather conditions for the treatment and control groups. The last column illustrates the $t$-test results. Both the intercity and intracity migration intensityin the treatment group are significantly lower than those in the control group, while no significant differences in weather conditions are observed. The daily minimum temperature in most cities is 


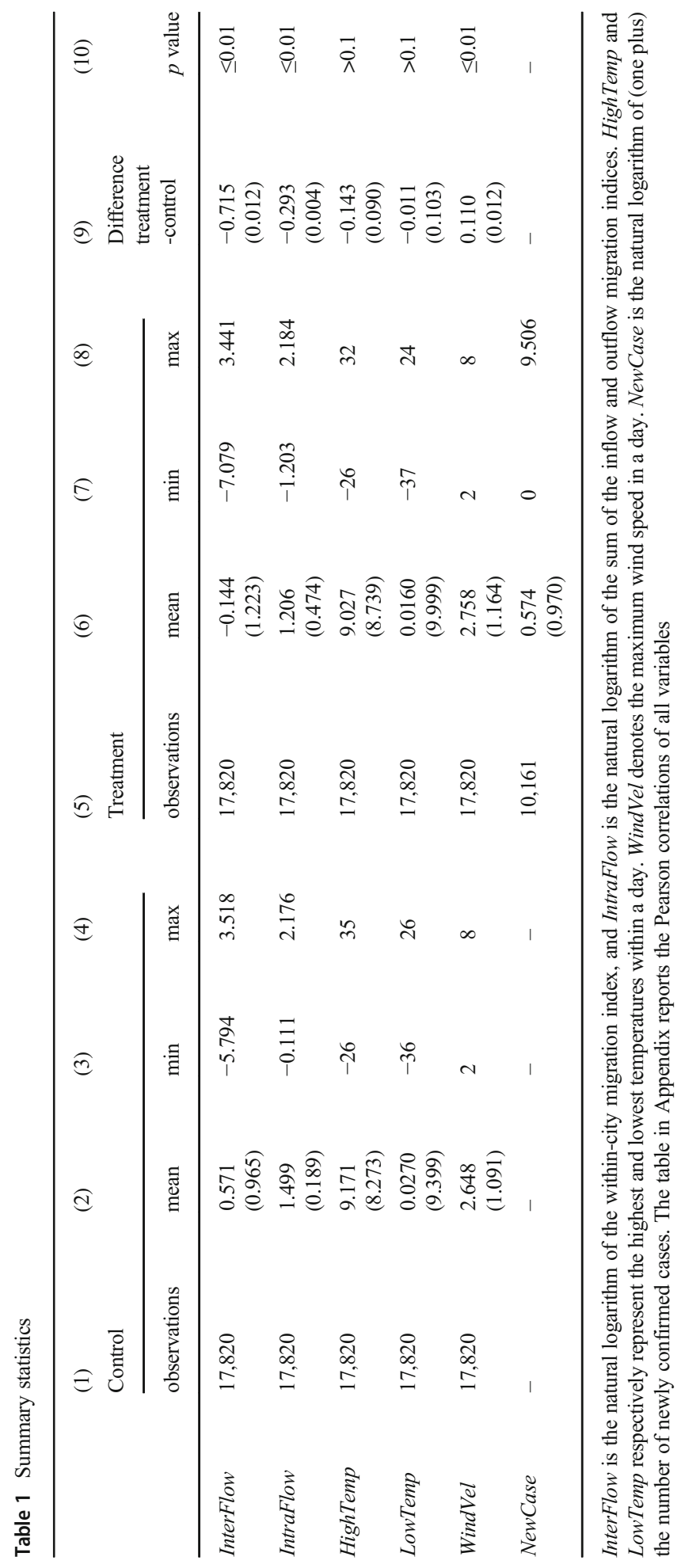


approximately 0 degrees Celsius, and the maximum wind force is at approximately 8 scales. Such elements affect the spread of COVID-19 [33, 34]. Therefore, these variables should be included in the empirical analysis to avoid omitted variable bias.

\section{Methodology}

Following Fang et al. [16], the difference-in-differences method is used to examine the impact of the first-level public health emergency response on human mobility:

$$
Y_{i, t}=\beta_{0}+\beta_{1} \cdot \text { Treat }^{*} \text { Post }_{i, t}+\beta_{2} \cdot \text { Treat }_{i}+\beta_{3} \cdot \text { Post }_{t}+\theta \cdot X_{i, t}+\gamma_{i}+\delta_{t}+\varepsilon_{i, t}(1)
$$

where $Y_{i, t}$ represents city $i$ 's human mobility on date $t$, including intercity migration intensity and intracity migration intensity, as alternative dependent variables. Treat $t_{i}$ is a dummy variable that equals one if the observation is among the statistics in 2020 and zero otherwise. As the characteristics of human mobility during the Spring Festival travel rush are almost identical each year, this paper uses Baidu's migration database in the lunar calendar Spring Festival in 2019 to compare with the situation in 2020. Post $_{t}$ is a dummy variable that equals one if the corresponding time is after the first-level public health emergency response and zero otherwise. For the sample in 2019, we use the corresponding method to define Post . Table 2 demonstrates the launch time of each province that has implemented the emergency health response. Although Hubei Province announced its implementation on January 24, 2020, its capital city, Wuhan, actually took strict travel restrictions on January 23, 2020. Treat $*$ Post $_{i, t}$ is the interaction term of treat $_{i}$ and post $_{t}$, and the coefficient $\beta_{1}$ captures the treatment effects. $X_{i, t}$ represents the weather conditions in city $i$ on date $t$, including maximum and minimum temperature, wind direction, and wind speed. $\gamma_{i}$ is city fixed effects to control for time-invariant, unobserved city characteristics, and $\delta_{t}$ is daily fixed effects to control for trends that shape human mobility over time.

The methodology used above quantifies the average effects of the first-level public health emergency response, but it can hardly capture trends after its

Table 2 The launch time of the policy

The launch time of the first-level public Provinces health emergency response policy

January 23, 2020

January 24, 2020

January 25, 2020

January 30, 2020
Guangdong, Zhejiang, Hunan, Hubei (Wuhan)

Shandong, Anhui, Hubei, Beijing, Tianjin, Shanghai, Chongqing, Jiangxi, Sichuan, Yunnan, Guizhou, Fujian, Hebei, Guangxi, Jiangsu

Hainan, Xinjiang, Henan, Heilongjiang, Gansu, Liaoning, Shanxi, Shaanxi, Qinghai, Jilin, Ningxia, Inner Mongolia Tibet

The launch time of the first-level public health emergency response policy across different provinces was collected by the authors 
implementation. As a result, we use the following identification strategy to conduct the event study analysis:

$$
Y_{i, t}=\beta_{0}+\sum_{k=-14}^{14} \beta_{k} \cdot \tau_{k}+\theta \cdot X_{i, t}+\gamma_{i}+\delta_{t}+\varepsilon_{i, t}
$$

The definitions of $Y_{i, t}, X_{i, t}, \gamma_{i}$ and $\delta_{t}$ follow Eq. (1). $k$ represents the time interval of the implementation of the first-level public health emergency response. $\tau_{k}$ is a dummy variable taking the value of one if the time interval equals $k$; otherwise, it is zero. $\tau_{k}$ equals one if $k \geq 14$, as we take for granted that the treatment effects of the policy longer than 14 days are the same as the treatment effects for 14 days. After detrending and centering the estimates one day prior to the policy implementation, we can capture the results for dynamic effects. Thus, the key coefficient $\beta_{k}$ represents the treatment effects in different time periods.

\section{Empirical Results}

\section{Baseline Estimation Results}

After the implementation of the health emergency response, quarantine stations were established on highways and main roads, thus restricting human mobility to some extent. Therefore, this paper analyzes the effect of the policy on human mobility. Table 3 illustrates that there are significant decreases in both intercity and intracity migration in the presence of a full set of control variables and city and daily fixed effects. The scale of intercity migration has dropped by $10.4 \%$, and the scale of intracity migration has decreased by $10.5 \%$, illustrating that the first-level public health emergency response does control human mobility.

To measure the treatment effects dynamically in different time periods, this paper further employs Eq. (2) and uses intercity and intracity migration as dependent variables. Figs. 2 and 3 show $\beta_{k}$ as the treatment effects. From the figures, after the announcement of the emergency health response, there are significant and long-lasting decreasing trends in both intercity and intracity migration, which become increasingly larger over time. With a limited understanding of COVID-19, governments implemented such policies to ensure policy outcomes. At the very beginning, some citizens held skeptical attitudes toward the isolation policy and participated in parties and gatherings. With the development of COVID-19, citizens started to realize the seriousness and willingly adopted the isolation policy to further decrease human mobility, thus explaining a larger magnitude of the policy effects over time.

The above figures show that after implementation, there is a significant decreasing trend in the scale of human mobility. To further analyze the impacts of human mobility on the control of COVID-19, we analyze the influences of human mobility from Wuhan and other cities in Hubei Province on the number of newly confirmed cases in other cities. The following identification strategy is set to solve the problem: 
Table 3 Baseline estimation results

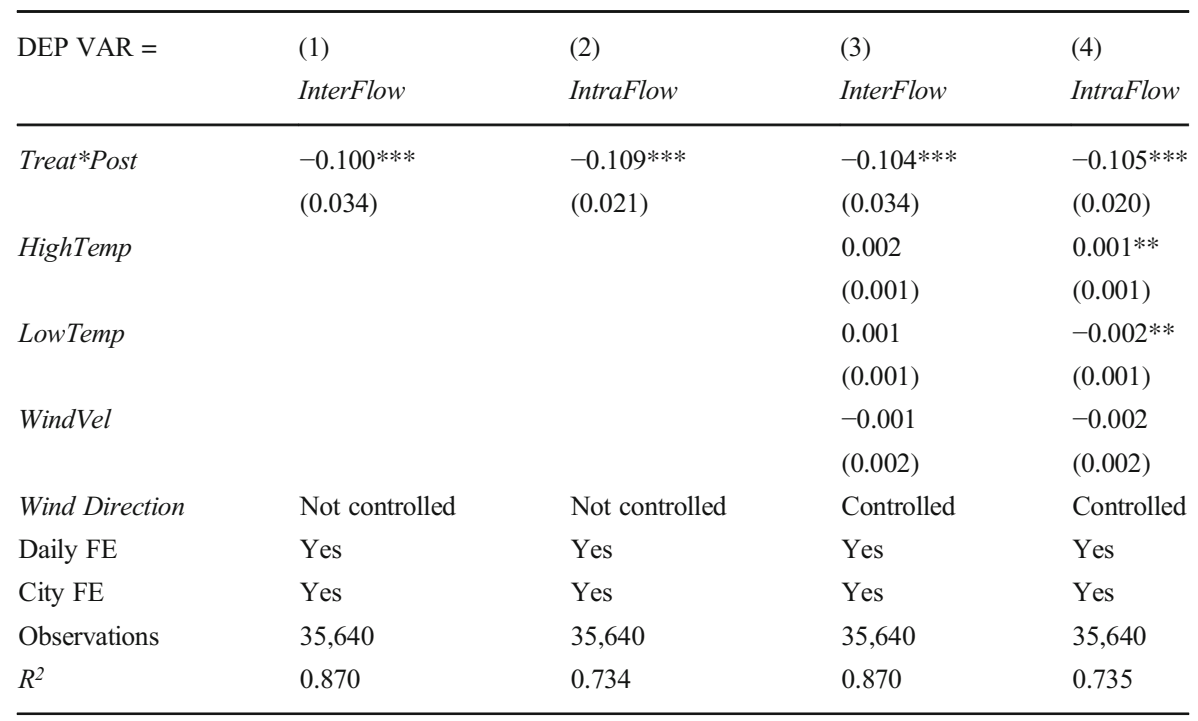

This table contains the estimated results utilizing Eq. (1). Columns (1) and (2) respectively use InterFlow and IntraFlow as the dependent variable in the presence of city and daily fixed effects. Columns (3) and (4) extend columns (1) and (2) to include a full set of control variables. Robust standard errors are clustered by city in parentheses. $*, * *$, and $* * *$ respectively denote significance levels of $10 \%, 5 \%$ and $1 \%$

$$
Y_{i, t}=\beta_{0}+\sum_{k=-14}^{0} \beta_{t} \cdot \text { inflow }_{i . t-k}+\theta \cdot X_{i, t}+\gamma_{i}+\delta_{t}+\varepsilon_{i, t}
$$

where $Y_{i, t}$ represents the natural logarithm of (one plus) the number of newly confirmed cases each day in city $i$. inflow $_{i, t-k}$ represents the immigrant index from the epicenter to city $i$, which is calculated from the product of the immigrant index and the proportion of inflows from Hubei Province or Wuhan (we further extend to two other cities in Hubei). The sample used comes from statistics outside Hubei Province and other cities. The following figure demonstrates the impacts of inflows from the epicenter on the newly confirmed cases in other Chinese cities.

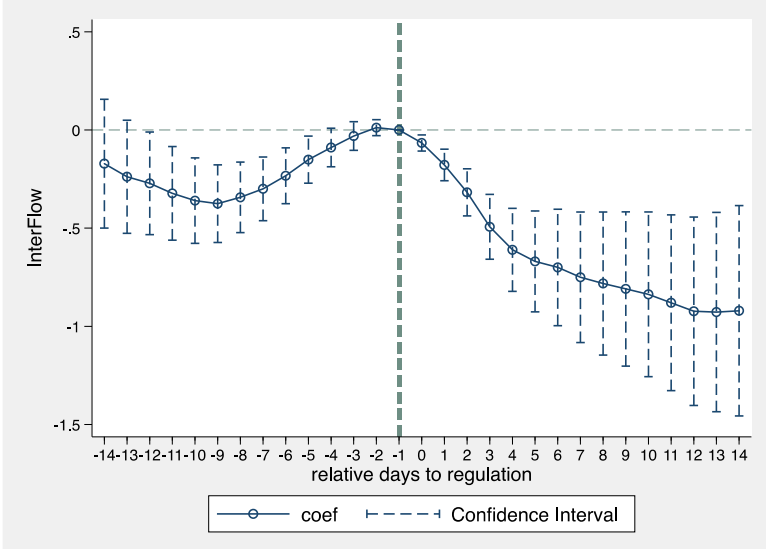

Fig. 2 Event study analysis of intercity mobility intensity 


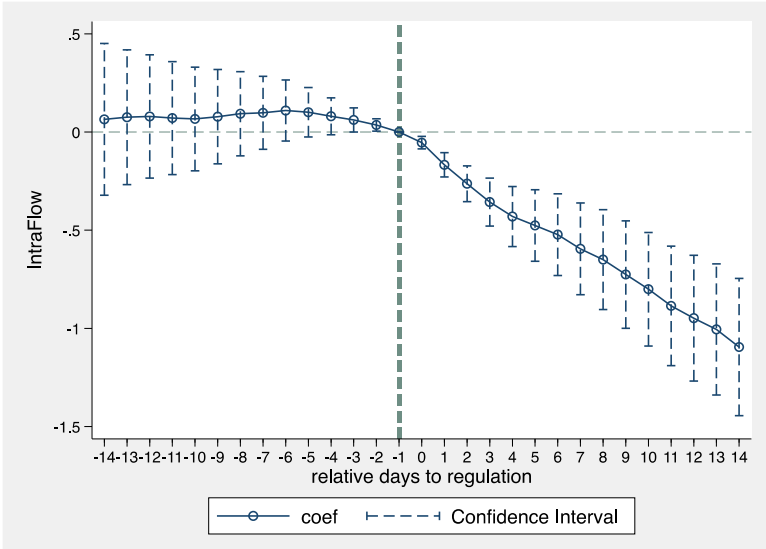

Fig. 3 Event study analysis of intracity mobility intensity

Figure 4 shows the impacts of human mobility from Huanggang, Xiaogan, Wuhan, and Hubei Province on the control of newly emerged infected cases. Wuhan, Huanggang and Xiaogan are the top three cities with the most infected cases in Hubei Province. Considering the trend of newly emerging cases, it is clear that the trend of inflows and outflows from Hubei Province to other provinces is consistent with the mobility trends from Wuhan to other cities outside Hubei Province. The results suggest that human mobility from Wuhan has crucial impacts on the spread of COVID-19. Thus, control of human mobility at the epicenter has important effects on the control of the pandemic.

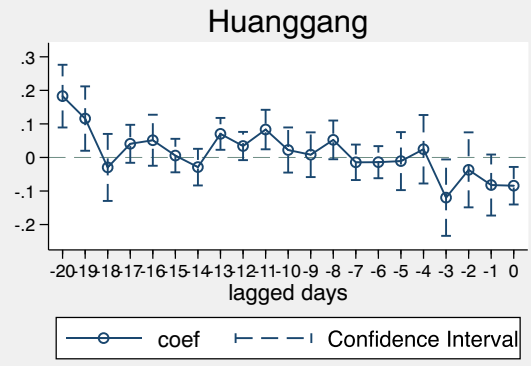

Wuhan

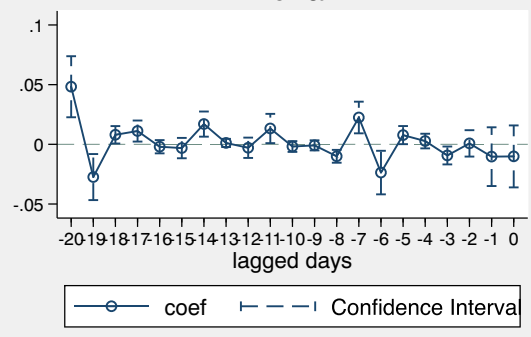

Xiaogan

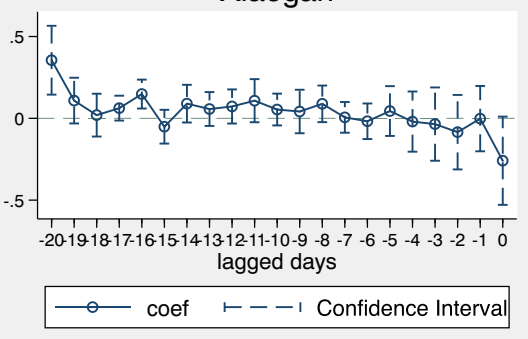

Hubei

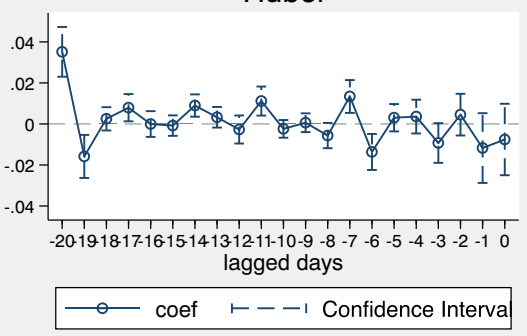

Fig. 4 The impact of immigration on newly confirmed cases in destination cities 
There is a positive influence of the inflows from Hubei Province or Wuhan on local newly confirmed infected cases, which shows a significant promoting effect of human mobility on the spread of COVID-19. The above figure illustrates that there is a lagged effect on the inflows from the epicenter on newly confirmed cases, as the incubation period of 2019-nCoV is relatively long, which takes some time to be confirmed.

The impact of the first-level public health emergency response on the control of COVID-19 is further examined by utilizing an event study. The specific identification strategy is as follows:

$$
Y_{i, t}=\beta_{0}+\sum_{k=-4}^{28} \beta_{k} \cdot \tau_{k}+\theta \cdot X_{i, t}+\gamma_{i}+\delta_{t}+\varepsilon_{i, t}
$$

where $Y_{i, t}$ presents the natural logarithm of (one plus) the number of newly confirmed cases each day. According to clinical data on the epidemic in Wuhan from the statistics of Yang et al. [35], the mean duration of the incubation period is 4.8 days, and the mean time from showing symptoms to confirmation is 5 days. As a result, this paper anticipates that it will take approximately 10 days to affect the epidemic after the implementation of the first-level public health emergency response in each province. Additionally, both the insufficient contingency reservation of medical facilities and the negligence of officials lead to great underestimation of the number of newly confirmed cases within Hubei Province. Therefore, an event study is utilized to overcome the disturbances of newly confirmed cases in Hubei Province to eliminate the possible influences on treatment effects. The definition of $\tau_{k}$ is consistent with that in Eq. (2). $\beta_{k}$ represents the treatment effects in different time periods, the window of which is from 4 days before the policy implementation to 28 days after its implementation and includes the sample in the treatment group (of the statistics in 2020 only). The estimation of $\beta_{k}$ is demonstrated in Fig. 5 .

It is illustrated in Fig. 5 that newly confirmed infected cases show an upward trend after implementing the emergency health response. These infected cases are caused by either a history of contact with cases in Hubei Province or other reasons, leading to infection before the imposition of the policy. Ten days after the restriction of human mobility, the number of newly confirmed cases exhibits an inflection point, and over

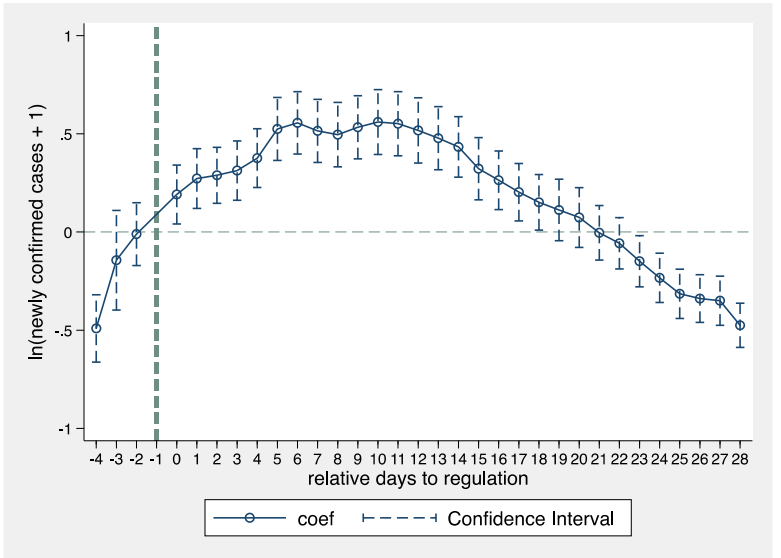

Fig. 5 The lockdown effect on the spread of COVID-19 
time, the downward trend becomes increasingly apparent until the 21st day, when it is negative. Considering that there is a lagged phase between infection and confirmation, the trend shown in Figs. 2 and 3 is consistent with the scale of human mobility, which suggests that the restriction on human mobility has significant impacts on the control of epidemics.

\section{Robustness Check}

With the influences of the Spring Festival, the common trend between the treatment group and control group ensures that the migration data are comparable. Figures 6 and 7 examine the common trend between the intercity and intracity migration indices. The upper-left graph depicts the intercity migration situation where the policy was implemented on January 23, 2020, while the upper-right graph shows that for January 24. The lower-left and lower-right graphs respectively illustrate the situation where the policy was implemented on January 25 and January 30. Figure 7 presents the situation of intracity migration in the same order as in Fig. 6. Both figures show that the premise of a common trend is satisfied between the treatment and control groups.

This study then splits the sample to avoid possible upward bias toward the treatment effects caused by special circumstances in some cities. As the epicenter, Wuhan imposes stricter restrictions that may affect the estimation, and thus, this paper aims to quantify human mobility by excluding Wuhan. Columns 1 and 2 of Table 4 illustrate that the scale of human mobility drops significantly with the implementation of the first-level public health emergency response. Columns 3 and 4 report the treatment effects with the exclusion of 12 municipalities in Hubei Province, showing that intercity and intracity migration fall significantly. As the epidemic in Hubei Province is more
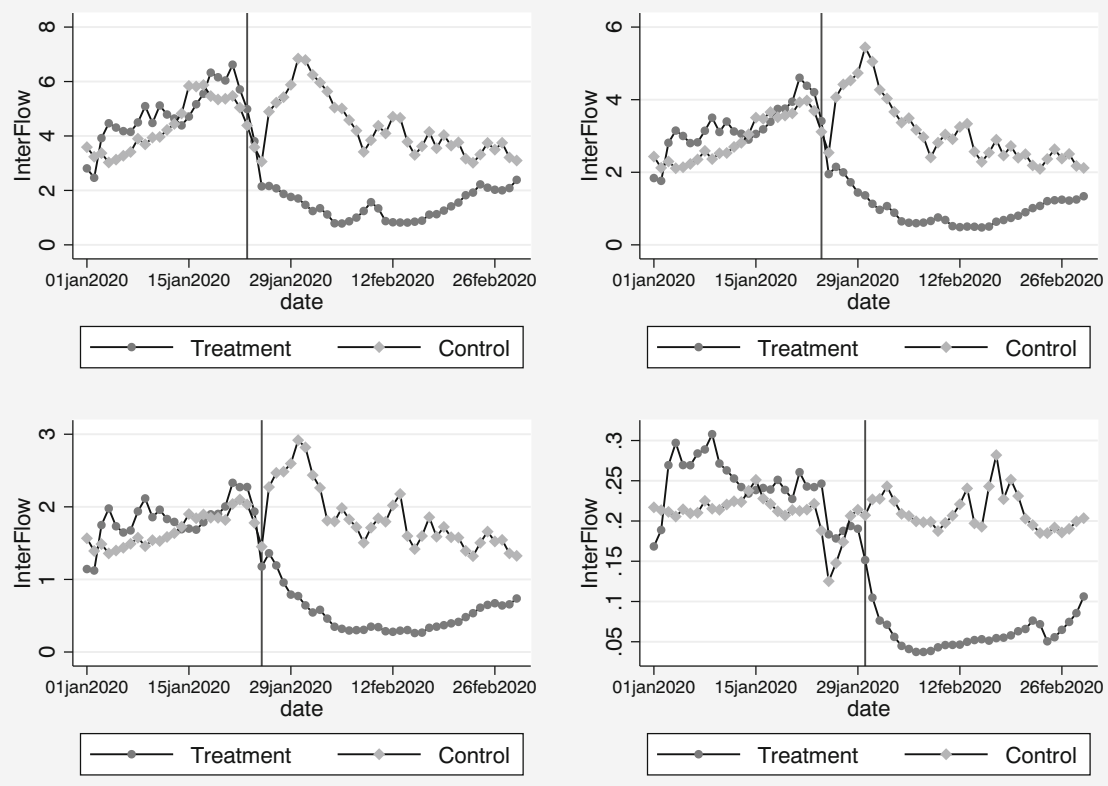

Fig. 6 Common trend in the intercity migration index 

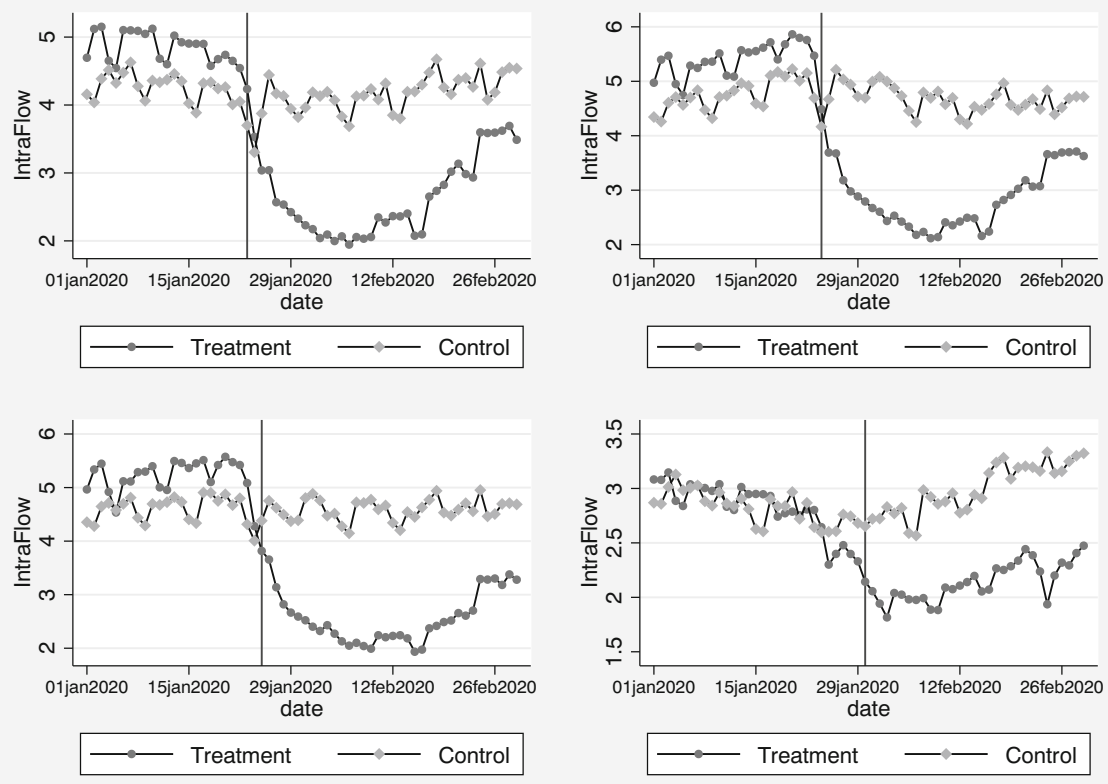

Fig. 7 Common trend in the intracity migration index

severe than that in any other city in China, the government in Hubei imposes more restrictions on human mobility. With the combination of the estimation, it is fair to conclude that the first-level public health emergency response takes effect in each province as it realizes human mobility restrictions in China. Considering that the selection of treatment and control groups might lead to possible pitfalls, time-varying control variables (i.e., public opinions, social media exposure and search index) could reduce the ability to make causal inferences. Thus, we have included the interaction between city fixed effects and year fixed effects in columns 5 and 6 to control the unobservable variables that may affect the robustness of the estimation [36]. As the data we utilize are on a daily level, the possible confounding factors have been absorbed by daily fixed effects. The treatment effects including the interaction between city and year fixed effects are consistent with the baseline results reported in Table 3.

\section{Heterogeneity Analysis}

The transportation infrastructure, economic condition, and population density of different cities in China vary considerably, ${ }^{2}$ which affect human mobility and the transmission of infectious diseases. In general, the level of convenience of transportation and the density of the population have more direct effects on mobility restrictions, while the effect of economic conditions is not as obvious. In practice, however, in developed regions, citizens can comply with an isolation policy by working from home

\footnotetext{
${ }^{2}$ For example, the population density of Nanjing is 991.35 people per square kilometer, while the corresponding number in Urumqi is only 193.65.
} 
Table 4 Robustness check

\begin{tabular}{lllllll}
\hline DEP VAR $=$ & $(1)$ & $(2)$ & $(3)$ & $(4)$ & $(5)$ & $(6)$ \\
& InterFlow & IntraFlow & InterFlow & IntraFlow & InterFlow & IntraFlow \\
\hline Treat*Post & $-0.105^{* * *}$ & $-0.101^{* * *}$ & $-0.098^{* * *}$ & $-0.105^{* * *}$ & $-0.124^{* * * *}$ & $-0.108^{* * * *}$ \\
& $(0.034)$ & $(0.020)$ & $(0.033)$ & $(0.020)$ & $(0.035)$ & $(0.019)$ \\
Control & Yes & Yes & Yes & Yes & Yes & Yes \\
$\quad$ Variables & & & & & & \\
Daily FE & Yes & Yes & Yes & Yes & Yes & Yes \\
City FE & Yes & Yes & Yes & Yes & Yes & Yes \\
City FE*Year & No & No & No & No & Yes & Yes \\
FE & & & & & & \\
Sample & Without & Without & Without Hubei & Without Hubei & Full & Full \\
\multicolumn{1}{l}{ Observations } & 35,520 & 35,520 & 34,200 & 34,200 & 35,640 & 35,640 \\
$R^{2}$ & 0.872 & 0.739 & 0.884 & 0.741 & 0.893 & 0.784 \\
\hline
\end{tabular}

The regression specification follows columns (3) and (4) of Table 3. Columns (1) and (2) exclude observations from Wuhan. Columns (3) and (4) exclude observations from Hubei Province. Columns (5) and (6) use the full sample and further include an interaction term of city and year fixed effects. Robust standard errors are clustered by city in parentheses. $*, * *$, and $* * *$ respectively denote significance levels of $10 \%, 5 \%$ and $1 \%$

or even taking vacation time, while in less developed regions, citizens who normally undertake manual labor and have a weaker capacity to cope with economic losses due to the epidemic have little ability to stay at home and effectively follow isolation instructions [37]. Therefore, this section examines the city-level heterogeneous effect on mobility restriction in order to identify the effect of regional socioeconomic conditions on the policy.

In addition, according to the literature review, the implementation effect of mobility restrictions is also affected by the emphasis on epidemics by local officials and citizens. A clear identification of this difference can improve the formation of policies for dealing with pandemics in the future. Therefore, this paper innovatively proposes that public awareness of the severity of COVID-19 will have an impact on the effectiveness of restriction policies. Specifically, when citizens have related experience with SARS or the regions they are living in have a higher frequency of identified COVID-19 cases, then the emphasis on this epidemic is greater, leading to a willingness to follow the required mobility restrictions.

Considering that human mobility has a close relationship with transportation infrastructure, regional development, and population density, this paper will further examine the treatment effects in different regions with a combination of city-level socioeconomic characteristics. The data on the city-level characteristics are derived from the China City Statistical Yearbook 2018. Table 5 then illustrates the treatment effects in different cities. Large cities are defined as regions where the highway passenger capacity, the level of GDP, or the population density is above the 50th percentile. Panel A shows that both intercity and intracity migration experience a drop in developed communication regions since the travel restrictions caused by the first-level public health emergency response lead to the suspension of passenger buses, which exerts more evident treatment effects on human mobility restrictions in more convenient 
regions. Panel B reconfirms that the treatment effects are larger in developed regions, utilizing income level as a proxy. The results in Panel $\mathrm{C}$ suggest that the scale of human mobility in regions with denser populations is lower, with greater magnitudes and significance, which indicates that the first-level public health emergency response is better implemented and able to prevent the spread of an epidemic on a large scale. Based on this table, the first-level public health emergency response exerts larger impacts on larger cities with respect to considerations of transportation, economic development and population density.

Table 5 Heterogeneity analysis - socioeconomic characteristics

\begin{tabular}{|c|c|c|c|c|}
\hline \multirow[t]{2}{*}{ DEP VAR = } & (1) & & & \\
\hline & InterFlow & IntraFlow & InterFlow & IntraFlow \\
\hline \multicolumn{5}{|l|}{ Panel A } \\
\hline & \multicolumn{2}{|c|}{ More convenient area } & \multicolumn{2}{|c|}{ Less convenient area } \\
\hline \multirow[t]{2}{*}{ Treat*Post } & $-0.111 * * *$ & $-0.109 * * *$ & $-0.098^{*}$ & $-0.090 * * *$ \\
\hline & $(0.025)$ & $(0.034)$ & $(0.057)$ & $(0.024)$ \\
\hline Control Variables & Yes & Yes & Yes & Yes \\
\hline Daily FE & Yes & Yes & Yes & Yes \\
\hline City FE & Yes & Yes & Yes & Yes \\
\hline Observations & 17,280 & 17,280 & 17,160 & 17,160 \\
\hline$R^{2}$ & 0.867 & 0.734 & 0.883 & 0.748 \\
\hline
\end{tabular}

Panel B

\begin{tabular}{|c|c|c|c|c|}
\hline \multirow{3}{*}{ Treat*Post } & \multicolumn{2}{|c|}{ More developed area } & \multicolumn{2}{|c|}{ Less developed area } \\
\hline & $-0.118 * * *$ & $-0.098 * * *$ & -0.073 & 0.001 \\
\hline & $(0.029)$ & $(0.030)$ & $(0.054)$ & $(0.017)$ \\
\hline Control Variables & Yes & Yes & Yes & Yes \\
\hline Daily FE & Yes & Yes & Yes & Yes \\
\hline City FE & Yes & Yes & Yes & Yes \\
\hline Observations & 17,520 & 17,520 & 17,400 & 17,400 \\
\hline$R^{2}$ & 0.876 & 0.765 & 0.871 & 0.776 \\
\hline \multicolumn{5}{|l|}{ Panel C } \\
\hline & \multicolumn{2}{|c|}{ More intensive population } & \multicolumn{2}{|c|}{ Less intensive population } \\
\hline \multirow[t]{2}{*}{ Treat*Post } & $-0.121 * * *$ & $-0.145^{* * * *}$ & $-0.104 * *$ & -0.029 \\
\hline & $(0.028)$ & $(0.036)$ & $(0.051)$ & $(0.018)$ \\
\hline Control Variables & Yes & Yes & Yes & Yes \\
\hline Daily FE & Yes & Yes & Yes & Yes \\
\hline City FE & Yes & Yes & Yes & Yes \\
\hline Observations & 17,760 & 17,760 & 17,760 & 17,760 \\
\hline$R^{2}$ & 0.875 & 0.762 & 0.872 & 0.731 \\
\hline
\end{tabular}

The regression specification follows columns (3) and (4) of Table 3. Panel A splits the sample according to the highway passenger capacity. Panel B splits the sample according to income level. Panel $\mathrm{C}$ splits the sample according to the density of the population. Robust standard errors are clustered by city in parentheses. *, **, and $* * *$ respectively denote significance levels of $10 \%, 5 \%$ and $1 \%$ 
While most provinces in China announced the first-level public health emergency response by 30 January 2020, the intensity of human mobility restriction measures among different regions has varied given differences inlocalpublic awareness in two aspects. First, the implementation of mobility restriction measures depends on the cooperation of citizens. During the period of epidemic prevention and control, despite different levels of government-established immunization sites among residential communities and even the setup of roadblocks to minimize the traffic, local officials had difficulty maintaining and protecting the roadblocks in all types of weather. This then led to sabotage by citizens who were opposed to the measures, such as outdoor activities. This paper concerns that the severity mentioned above depends on citizens' recognition of epidemics. In general, if citizens agree that the epidemic is relatively severe, then they tend to support strict control measures or otherwise attempt to violate them. As a consequence, we use provincial-level SARS cases to explore the heterogeneous effect of public awareness under the premise that citizens living in the regions that had experienced SARS in 2003 relatively sufficiently realized the seriousness of the epidemic and acted cautiously; otherwise, they (those living in Heilongjiang, Hainan, Guizhou, Yunnan, Qinghai, Tibet, and Xinjiang) would be relatively ignorant about its severity. During the outbreak of SARS, mainland China reported a total of 5327 infected cases, 4959 cured cases and 349 deaths. The teaching schedules in numerous universities were disrupted. Primary schools and middle schools in Beijing and many other cities across the nation were suspended. Moreover, the existing admission process was changed to accommodate the special needs during the outbreak of SARS. For example, students in Beijing completed the application form after their examination scores were announced. At the peak of the SARS pandemic, traditional social forces in rural villages of China have had great effects on controlling the pandemic. Multiple restrictions were imposed to control the spread of the epidemic; for example, villages opened only to local residents. Furthermore, local migration workers were permitted to enter the village only after the observation period was finished. Those experiences of pandemic control have left people with memorable impressions and improved public health awareness of epidemic prevention and control. Panel A of Table 6 shows that mobility restriction measures were better implemented in the provinces with SARS cases in 2003, while the impact of the measures was relatively weak - the indicators of human mobility even do not change significantly.

Second, this paper has adopted the Baidu Search Index to measure public awareness of COVID-19 by citizens in different regions. The Baidu Search Index is based on the search volume of its users, taking COVID-19 as a key word weighted by the search frequency on different webpages utilizing the Baidu search engine. The search index provided by Baidu consists of two subindices: the PC search index and mobile search index. This paper employs a daily average value of the PC search index and mobile search index between January 1, 2020, and February 29, 2020. Panel B then reports the estimation results. Regions with a higher search index of COVID-19 have a significant drop in both inter- and intracity migration intensity. However, human mobility does not severely decrease in regions with a lower search index, which suggests that public awareness has had great effects on human mobility restrictions. This finding implies that promoting public awareness of epidemic severity plays a key role during the period of prevention and control. 
Table 6 Heterogeneity analysis - public awareness

\begin{tabular}{|c|c|c|c|c|}
\hline \multirow[t]{2}{*}{ DEP VAR = } & (1) & (2) & (3) & (4) \\
\hline & InterFlow & IntraFlow & InterFlow & IntraFlow \\
\hline \multicolumn{5}{|l|}{ Panel A } \\
\hline & \multicolumn{2}{|c|}{ Provinces with SARS cases } & \multicolumn{2}{|c|}{ Provinces without SARS cases } \\
\hline \multirow[t]{2}{*}{ Treat*Post } & $-0.059 * * *$ & $-0.083 * * *$ & -0.089 & -0.026 \\
\hline & $(0.021)$ & $(0.023)$ & $(0.097)$ & $(0.041)$ \\
\hline Control Variables & Yes & Yes & Yes & Yes \\
\hline Daily FE & Yes & Yes & Yes & Yes \\
\hline City FE & Yes & Yes & Yes & Yes \\
\hline Observations & 30,600 & 30,600 & 5040 & 5040 \\
\hline$R^{2}$ & 0.879 & 0.762 & 0.858 & 0.643 \\
\hline \multicolumn{5}{|l|}{ Panel B } \\
\hline & Provinces with higher & Baidu Search Index & Provinces with lower & Baidu Search Index \\
\hline \multirow[t]{2}{*}{ Treat*Post } & $-0.141 * * *$ & $-0.209 * * *$ & $-0.086^{*}$ & -0.025 \\
\hline & $(0.032)$ & $(0.035)$ & $(0.046)$ & $(0.019)$ \\
\hline Control Variables & Yes & Yes & Yes & Yes \\
\hline Daily FE & Yes & Yes & Yes & Yes \\
\hline City FE & Yes & Yes & Yes & Yes \\
\hline Observations & 14,520 & 14,520 & 21,120 & 21,120 \\
\hline$R^{2}$ & 0.860 & 0.744 & 0.887 & 0.751 \\
\hline
\end{tabular}

The regression specification follows columns (3) and (4) of Table 3. Panel A splits the sample according to whether the province had confirmed SARS cases in 2003. Panel B splits the sample according to Baidu Search Index volumes. Robust standard errors are clustered by city in parentheses. *, **, and *** respectively denote significance levels of $10 \%, 5 \%$ and $1 \%$

According to the requirement of the first-level public health emergency response mechanism, the emergency supervision of local governments is controlled by the provincial government. Provincial governments organize, supervise and lay out various specific plans, and therefore, their decision regarding to epidemics is quite significant. Table 7 shows an analysis of the heterogeneity of provincial leaders' work experience and tenure to present the impact of their background on the implementation of epidemic prevention and control. As we can see from Panel A, if both provincial leaders (provincial party secretaries and governors) have more than one year of work experience in the region in charge, then the intensity of mobility restriction measures is relatively high. This is because local work experience helps local leaders efficiently organize and cooperate with human resources to carry out effective control. This also indicates that we need to reconsider the method of political turnover once the crisis happens. In addition, if provincial leaders have work experience in health care disaster relief, then they would be aware of the epidemic, and their response capacity in the face of pandemic threats would be stronger. This is confirmed in Panel B. Last, the tenure of officials in China also has a significant incentive effect on their behavior. According to the regulation on provincial party secretaries and governors, those 
Table 7 Heterogeneity analysis - local leaders' characteristics

\begin{tabular}{lllll}
\hline DEP VAR $=$ & $(1)$ & $(2)$ & $(3)$ & $(4)$ \\
& InterFlow & IntraFlow & InterFlow & IntraFlow \\
\hline
\end{tabular}

Panel A

Both provincial leaders with more than 1 year of work experience in the region in charge

$\begin{array}{lll}\text { Treat*Post } & -0.108^{* *} & -0.105^{* * *} \\ & (0.042) & (0.023) \\ \text { Control Variables } & \text { Yes } & \text { Yes } \\ \text { Daily FE } & \text { Yes } & \text { Yes } \\ \text { City FE } & \text { Yes } & \text { Yes } \\ \text { Observations } & 24,120 & 24,120 \\ R^{2} & 0.868 & 0.700\end{array}$

Panel B

At least one provincial leader with experience working in health care disaster relief

$\begin{array}{lll}\text { Treat*Post } & -0.172 * * * & -0.215^{* *} \\ & (0.047) & (0.082) \\ \text { Control Variables } & \text { Yes } & \text { Yes } \\ \text { Daily FE } & \text { Yes } & \text { Yes } \\ \text { City FE } & \text { Yes } & \text { Yes } \\ \text { Observations } & 5040 & 5040 \\ R^{2} & 0.915 & 0.831\end{array}$

Panel C

Neither provincial leaders with the opportunity to serve a consecutive term

$\begin{array}{lll}\text { Treat*Post } & -0.127 * & -0.079 \\ & (0.069) & (0.047) \\ \text { Control Variables } & \text { Yes } & \text { Yes } \\ \text { Daily FE } & \text { Yes } & \text { Yes } \\ \text { City FE } & \text { Yes } & \text { Yes } \\ \text { Observations } & 3720 & 3720 \\ R^{2} & 0.851 & 0.629\end{array}$

At least one provincial leader without 1 year of work experience in the region in charge

$\begin{array}{ll}-0.011 & -0.077^{*} \\ (0.026) & (0.043) \\ \text { Yes } & \text { Yes } \\ \text { Yes } & \text { Yes } \\ \text { Yes } & \text { Yes } \\ 11,520 & 11,520 \\ 0.894 & 0.816\end{array}$

Neither provincial leaders with experience working in health care disaster relief

$\begin{array}{ll}-0.103 * * * & -0.092 * * * \\ (0.039) & (0.022) \\ \text { Yes } & \text { Yes } \\ \text { Yes } & \text { Yes } \\ \text { Yes } & \text { Yes } \\ 30,600 & 30,600 \\ 0.866 & 0.723\end{array}$

At least one provincial leader with the opportunity to serve a consecutive term

$\begin{array}{ll}-0.099 * * * & -0.119 * * * \\ (0.038) & (0.022) \\ \text { Yes } & \text { Yes } \\ \text { Yes } & \text { Yes } \\ \text { Yes } & \text { Yes } \\ 31,920 & 31,920 \\ 0.876 & 0.754\end{array}$

The regression specification follows columns (3) and (4) of Table 3. Panel A splits the sample according to whether the provincial leaders have been working in the region in charge for 1 year. Panel B splits the sample according to whether the provincial leaders have related experience in dealing with health care disasters. Panel $\mathrm{C}$ splits the sample according to whether the provincial leaders have the opportunity to serve a consecutive term. Robust standard errors are clustered by city in parentheses. *, **, and *** respectively denote significance levels of $10 \%, 5 \%$ and $1 \%$

aged 62 years can be promoted, those aged 63 can serve a consecutive term, those aged 64 are not allowed to remain in office, and those aged 65 should be terminated (this can be extended if their tenure is less than 3 years). This indicates 
that provincial leaders aged 64 and over have no opportunity to serve a consecutive term. Therefore, there is less motivation for them to make political achievements during epidemic prevention and control. The results of Panel $\mathrm{C}$ are again in support of our argument.

\section{Conclusion}

Using city-level human mobility data from China, this paper utilizes the difference-indifferences method to empirically examine the effect of the first-level public health emergency response on human mobility. Intercity and intracity migration intensities decline by $10.4 \%$ and $10.5 \%$, respectively. The results are still robust with the exclusion of the effects of Wuhan and other cities in Hubei Province, which suggests that controlling human mobility in the nation leads to a decrease in newly confirmed infected cases. Considering heterogeneity, restrictions on human mobility have a greater impact on economically developed areas, developed communication areas, or areas with dense populations. Moreover, mobility restriction measures are found to be better implemented in regions with public awareness of COVID-19, or areas with provincial leaders who have healthcare crisis experience, local administrative experience, or an opportunity to serve a second term.

Our results contribute to the literature in two ways. First, the intensity of mobility restriction measures is found to vary among different regions, as both the emphasis of local governments and their public awareness differ. Second, we show the first-level public health emergency response as one explanation of pandemic control in China, leading to an approximately $10 \%$ reduction in human mobility, and the discussion of heterogeneity sheds light on the countries that are currently suffering from the virus and that aim at future prevention.

One limitation of this paper is that our research has yet to identify clear mechanisms of how the first-level public health emergency response policy affects human mobility. However, our paper still points out several further research directions - the heterogeneity of treatment effects on different cities, such as how city characteristics influence the treatment effects of human mobility, and further, which policy would be more effective considering city-level heterogeneity. Another direction may quantify the impact of one specific policy, as we focus on the combined effects of a set of policies, for example, the policy of lockdowns and setting checkpoints, to determine which policy and how the combination of different policies could most effectively be used to control the spread of the pandemic. Moreover, welfare analysis focusing on the economic outcomes of the outbreak could be estimated, such as the economic cost of this pandemic, since the benefits of controlling the pandemic are widely examined in the existing literature.

One implication for practice from our results is that the central government is advised to strengthen the publicity and education of local officials and citizens, and to construct and optimize various public health emergency responses for each city given their local characteristics. In addition, the findings can suggest the need to establish rigid and effective public health measures, such as lockdowns, before the arrival of the next epidemic. 


\section{Appendix}

Table 8 Pearson correlations

\begin{tabular}{|c|c|c|c|c|c|c|}
\hline & InterFlow & IntraFlow & NewCase & HighTemp & LowTemp & WindVel \\
\hline InterFlow & 1.000 & & & & & \\
\hline IntraFlow & $\begin{array}{l}0.452 \\
(0.000)\end{array}$ & 1.000 & & & & \\
\hline NewCase & $\begin{array}{l}0.085 \\
(0.000)\end{array}$ & $\begin{array}{l}-0.408 \\
(0.000)\end{array}$ & 1.000 & & & \\
\hline HighTemp & $\begin{array}{l}0.120 \\
(0.000)\end{array}$ & $\begin{array}{l}-0.056 \\
(0.000)\end{array}$ & $\begin{array}{l}-0.021 \\
(0.033)\end{array}$ & 1.000 & & \\
\hline LowTemp & $\begin{array}{l}0.227 \\
(0.000)\end{array}$ & $\begin{array}{l}-0.021 \\
(0.000)\end{array}$ & $\begin{array}{l}0.045 \\
(0.000)\end{array}$ & $\begin{array}{l}0.900 \\
(0.000)\end{array}$ & 1.000 & \\
\hline WindVel & $\begin{array}{l}-0.121 \\
(0.000)\end{array}$ & $\begin{array}{l}-0.092 \\
(0.000)\end{array}$ & $\begin{array}{l}-0.018 \\
(0.063)\end{array}$ & $\begin{array}{l}-0.152 \\
(0.000)\end{array}$ & $\begin{array}{l}-0.172 \\
(0.000)\end{array}$ & 1.000 \\
\hline
\end{tabular}

\section{References}

1. Albertoni, N., and Wise, C. 2020. International trade norms in the age of Covid-19 nationalism on the rise? Fudan Journal of the Humanities and Social Sciences pp. 1-26.

2. Boylan, B.M., J. McBeath, and B. Wang. 2020. US-China relations: Nationalism, the trade war, and COVID-19. Fudan Journal of the Humanities and Social Sciences, 1-18. https://doi.org/10.1007/ s40647-020-00302-6.

3. Huang, Q. 2020. The pandemic and the transformation of Liberal international order. Journal of Chinese Political Science 1-26. https://doi.org/10.1007/s11366-020-09698-0.

4. Wang, Z., and Z. Sun. 2020. From globalization to regionalization: The United States, China, and the post-Covid-19 world economic order. Journal of Chinese Political Science 1-19. https://doi.org/10.1007/ s11366-020-09706-3.

5. Kermack, W.O., and A.G. McKendrick. 1927. A contribution to the mathematical theory of epidemics. Proceedings of the Royal Society of London. Series A, Containing Papers of a Mathematical and Physical Character 115 (772): 700-721.

6. Camitz, M. and Liljeros, F., 2005. The effect of travel restrictions on the spread of a highly contagious disease in Sweden. arXiv preprint q-bio/0505044.

7. Ferguson, N.M., D.A. Cummings, C. Fraser, J.C. Cajka, P.C. Cooley, and D.S. Burke. 2006. Strategies for mitigating an influenza pandemic. Nature 442 (7101): 448-452.

8. Bajardi, P., C. Poletto, J.J. Ramasco, M. Tizzoni, V. Colizza, and A. Vespignani. 2011. Human mobility networks, travel restrictions, and the global spread of 2009 H1N1 pandemic. PLoS One 6 (1): e16591.

9. Oster, E. 2012. Routes of infection: Exports and HIV incidence in sub-Saharan Africa. Journal of the European Economic Association 10 (5): 1025-1058.

10. Adda, J. 2016. Economic activity and the spread of viral diseases: Evidence from high frequency data. The Quarterly Journal of Economics 131 (2): 891-941.

11. Charu, V., S. Zeger, J. Gog, O.N. Bjørnstad, S. Kissler, L. Simonsen, B.T. Grenfell, and C. Viboud. 2017. Human mobility and the spatial transmission of influenza in the United States. PLoS Computational Biology 13 (2): e1005382.

12. Kraemer, M.U., C.H. Yang, B. Gutierrez, C.H. Wu, B. Klein, D.M. Pigott, L. Du Plessis, N.R. Faria, R. Li, W.P. Hanage, and J.S. Brownstein. 2020. The effect of human mobility and control measures on the COVID-19 epidemic in China. Science 368 (6490): 493-497. 
13. Hadjidemetriou, G.M., M. Sasidharan, G. Kouyialis, and A.K. Parlikad. 2020. The impact of government measures and human mobility trend on COVID-19 related deaths in the UK. Transportation Research Interdisciplinary Perspectives 6: 100167.

14. Lai, S., Ruktanonchai, N.W., Zhou, L., Prosper, O., Luo, W., Floyd, J.R., Wesolowski, A., Santillana, M., Zhang, C., Du, X. and Yu, H., 2020. Effect of non-pharmaceutical interventions for containing the COVID-19 outbreak in China. medRxiv.

15. Wang, C., Liu, L., Hao, X., Guo, H., Wang, Q., Huang, J., He, N., Yu, H., Lin, X., Pan, A. and Wei, S., 2020a. Evolving epidemiology and impact of non-pharmaceutical interventions on the outbreak of coronavirus disease 2019 in Wuhan, China. MedRxiv.

16. Fang, H., Wang, L. and Yang, Y., 2020. Human mobility restrictions and the spread of the novel coronavirus (2019-ncov) in china (no. w26906). National Bureau of Economic Research.

17. Chinazzi, M., Davis, J.T., Ajelli, M., Gioannini, C., Litvinova, M., Merler, S., y Piontti, A.P., Mu, K., Rossi, L., Sun, K. and Viboud, C., 2020. The effect of travel restrictions on the spread of the 2019 novel coronavirus (COVID-19) outbreak. Science, 368(6489), pp.395-400.

18. Tian, H., Y. Liu, Y. Li, C.H. Wu, B. Chen, M.U. Kraemer, B. Li, J. Cai, B. Xu, Q. Yang, and B. Wang. 2020. An investigation of transmission control measures during the first 50 days of the COVID-19 epidemic in China. Science 368 (6491): 638-642.

19. Chudik, A., M.H. Pesaran, and A. Rebucci. 2020. Voluntary and mandatory social distancing: Evidence on covid-19 exposure rates from chinese provinces and selected countries (no. w27039). Cambridge, MA: National Bureau of Economic Research.

20. Knittel, C.R. and Ozaltun, B. 2020. What does and does not correlate with COVID-19 death rates. medRxiv.

21. Kuchler, T., D. Russel, and J. Stroebel. 2020. The geographic spread of COVID-19 correlates with structure of social networks as measured by Facebook (no. w26990). Cambridge, MA: National Bureau of Economic Research.

22. Qiu, Y., X. Chen, and W. Shi. 2020. Impacts of social and economic factors on the transmission of coronavirus disease 2019 (COVID-19) in China. Journal of Population Economics 33: 1127-1172.

23. Brown, C.S., and M. Ravallion. 2020. Inequality and the coronavirus: Socioeconomic covariates of behavioral responses and viral outcomes across US counties (no. w27549). Cambridge, MA: National Bureau of Economic Research.

24. Cook, J., N. Newberger, and S. Smalling. 2020. The spread of social distancing. Economics Letters 196: 109511-109511.

25. Givens, J.W., and E. Mistur. 2020. The sincerest form of flattery: Nationalist emulation during the COVID-19 pandemic. Journal of Chinese Political Science, 1-22. https://doi.org/10.1007/s11366-02009702-7.

26. Makarychev, A., and T. Romashko. 2020. Precarious sovereignty in a post-liberal Europe: The COVID19 emergency in Estonia and Finland. Chinese Political Science Review 1-23. https://doi.org/10.1007/ s41111-020-00165-y.

27. Besley, T., and A. Case. 1992. Incumbent behavior: Vote seeking, tax setting and yardstick competition (no. w4041). Cambridge, MA: National bureau of economic research.

28. Li, H., and L.A. Zhou. 2005. Political turnover and economic performance: The incentive role of personnel control in China. Journal of Public Economics 89 (9-10): 1743-1762.

29. Besley, T., J.G. Montalvo, and M. Reynal-Querol. 2011. Do educated leaders matter? The Economic Journal 121 (554): F205-F227.

30. Brint, S., and S.R. Yoshikawa. 2017. The educational backgrounds of American business and government leaders: Inter-industry variation in recruitment from elite colleges and graduate programs. Social Forces 96 (2): 561-590.

31. Goodall, A.H., L.M. Kahn, and A.J. Oswald. 2011. Why do leaders matter? A study of expert knowledge in a superstar setting. Journal of Economic Behavior \& Organization 77 (3): 265-284.

32. Jones, B.F., and B.A. Olken. 2005. Do leaders matter? National leadership and growth since world war II. The Quarterly Journal of Economics 120 (3): 835-864.

33. Lowen, A.C., and J. Steel. 2014. Roles of humidity and temperature in shaping influenza seasonality. Journal of Virology 88 (14): 7692-7695.

34. Wang, M., Jiang, A., Gong, L., Luo, L., Guo, W., Li, C., Zheng, J., Li, C., Yang, B., Zeng, J. and Chen, Y., 2020b. Temperature significant change COVID-19 transmission in 429 cities. MedRxiv.

35. Yang, Y., Lu, Q., Liu, M., Wang, Y., Zhang, A., Jalali, N., ... \& Zhang, X. (2020). Epidemiological and clinical features of the 2019 novel coronavirus outbreak in China. MedRxiv.

36. Moser, P., and A. Voena. 2012. Compulsory licensing: Evidence from the trading with the enemy act. American Economic Review 102 (1): 396-427. 
37. Brown, C.S., Ravallion, M. and Van De Walle, D., 2020. Can the World's Poor Protect Themselves from the New Coronavirus? (no. w27200). Cambridge, MA: National Bureau of Economic Research.

Xiaoming Zhang is a postgraduate student in the Economic Department at the University of Chinese Academy of Social Sciences, majoring in economics. His research interests are in public policy analysis, innovation economics and related studies. He received his undergraduate degree in Science and undergraduate degree in Economics from the Renmin University of China. One of his research work has been published in Applied Economics Letters.

Dr. Weijie Luo is an assistant professor in economics at the Central University of Finance and Economics (CUFE). Prior to joining CUFE, Dr. Luo was a visiting researcher in economics at the University of Cambridge, and worked as an associate lecturer in economics at the University of York, where he completed his $\mathrm{PhD}$ in economics. His research interests are in macroeconomics, public economics, and economic policy. His research work has been published (or accepted for publication) in journals such as Economics Letters, Journal of Applied Economics, Applied Economics Letters, etc. He is currently serving as an anonymous referee in journals such as Journal of Applied Economics, Public Finance Review, etc.

Jingci Zhu is an undergraduate student in Economics (dual degree) in the National School of Development, Peking University. She received her B.A. in English (with Finance and Economics) at the Central University of Finance and Economics. Her research areas of interest are in development economics, innovation economics, and industrial organization. Her research work has been published in journals such as Applied Economics, Applied Economics Letters, etc. 